\title{
TEORIA ENUNCIATIVA DE BENVENISTE E SEMIÓTICA DISCURSIVA: CONTRIBUIÇÕES PARA A ANÁLISE DE TEXTOS
}

\section{Benveniste's enunciative theory and discursive semiotics: contributions for the analysis of texts}

\author{
Jorge Gabriel SARTINI POPOFF ${ }^{63}$ \\ Arnaldo CORTINA ${ }^{64}$
}

Resumo | Este artigo propõe examinar alguns conceitos inerentes à teoria enunciativa de Émile Benveniste com o intuito de observar como foram importantes para o desenvolvimento do nível discursivo do percurso gerativo do sentido na análise semiótica de textos. Pretendese, para tanto, descrever os conceitos propostos pelo referido autor, no que diz respeito à enunciação, e verificar seus desdobramentos na proposta da semiótica discursiva. Com o intuito de observar, por fim, a questão da enunciação a partir dos desenvolvimentos implementados pela semiótica, será apresentada uma breve análise de um texto da revista Gazelle, que faz parte de uma pesquisa mais ampla sobre o tema.

Palavras-chave | Enunciação. Enunciado. Discurso. Texto. Análise.
Abstract | This article proposes to examine some concepts inherent to Émile Benveniste's enunciative theory in order to observe how they were important for the development of the discursive level of the proposal of the generative process of meaning in semiotics for the analysis of texts. In order to do so, it is intended to describe the concepts proposed by the aforementioned author with regard to the issue of enunciation and to verify the unfolding of the proposal of discursive semiotics. In order to observe, finally, the issue of enunciation from the developments implemented by semiotics, a brief analysis of a text of the journal Gazelle, which is part of a broader research on the subject, will be presented.

Keywords | Enunciation. Enunciate. Discourse. Text. Analysis.

63 Sartini Popoff. UNESP. Endereço eletrônico: popoff2006@hotmail.com. ORCID ID: https://orcid. org/0000-0001-9602-1217.

64 Cortina. UNESP. Endereço eletrônico: arnaldo.cortina@unesp.br. ORCID ID: https://orcid.org/00000001-9404-8352 
- Teoria enunciativa de Benveniste e semiótica discursiva: contribuições para a análise de textos

\section{Introdução}

Examinar um objeto pelo olhar de uma teoria significa depreender um resultado particular ao seu escopo de análise. Ao fornecer as bases da Linguística moderna, Saussure (1980) já apontara para essa natureza epistemológica inerente às ciências, quando discutiu o fato de o ponto de vista preceder o objeto analisado. Para ele, o fenômeno da linguagem, multiforme e heteróclito, encontra homogeneidade na língua, estruturada enquanto sistema de valor, em que o sistema de signos se organiza. Esse postulado, que tem como ponto de partida o exame da dupla face do signo - seu significado e seu significante -, tem lugar nas dicotomias próprias dessa escolha (diacronia e sincronia, sociabilidade e individualidade, etc.).

Colocar em relevo a língua, no entanto, levou os herdeiros da linguística saussureana a deixarem de lado a dimensão subjetiva, a intersubjetiva e o agenciamento do sistema concreto dos signos. Passado um certo tempo, as teorias enunciativas voltaram-se para o individual e o atualizável da língua para desenvolverem seu conteúdo epistemológico.

Na esteira dessa reflexão, a escolha teórica deste trabalho no quadro das teorias enunciativas pretende considerar o fenômeno da enunciação como uma manifestação não-repetível da linguagem. Em se tratando especificamente da teoria de Émile Benveniste, implica, portanto, considerar que a enunciação é entendida como um ato individual e atualizável da língua, na sua dimensão oral e escrita, sendo o enunciado o produto do agenciamento dos signos na instância própria do discurso (COSTA e SILVA; ENDRUWEIT, 2011).

Se a língua é sempre atualizada nos diferentes usos que realizam seus interlocutores, cada enunciado será cada vez único e irrepetível, o que corresponde, no entanto, a um problema em se tratando de pensar um método para a teoria de Benveniste, uma vez que esse autor analisou o fenômeno da enunciação sem sistematizar a priori uma metodologia de análise de suas manifestações em textos, ficando a cargo da semiótica, por exemplo, definir um percurso que abordasse a significação no espectro da enunciação nos enunciados.

Nosso objetivo aqui será examinar como Émile Benveniste trata algumas questões centrais da enunciação e observar como a semiótica discursiva, oriunda dos trabalhos de Algirdas Julien Greimas, desenvolve essa questão para investigar a produção de sentido do texto. 


\section{Teoria da Enunciação de Benveniste}

A questão da enunciação linguística aparece dividida em um conjunto de ensaios reunidos durante quatro décadas no volume Princípios de Linguística Geral. Embora seja possível examinar os aspectos que Benveniste levanta sobre a enunciação em momentos distintos de sua teoria ${ }^{65}$, procuraremos aqui unificar suas preocupações teóricas em torno da enunciação, para que esse levantamento possa servir de base para o que apresentaremos a respeito das teorias que tratam posteriormente desse mesmo problema.

Comecemos por examinar primeiramente a teoria de Benveniste enquanto teoria da intersubjetividade, pois sua problemática envolve a natureza dos pronomes no processo de subjetividade ${ }^{66}$, em que as marcas de pessoa eu-tu são tidas como constitutivas da linguagem e de sua produção. Entende-se produção a partir do ponto em que tais marcas são mobilizadas segundo o estatuto do locutor que se instaura na linguagem, fazendo-se sujeito. Para Benveniste (2015, p. 286), a subjetividade "não é mais que a emergência no ser de uma propriedade fundamental da linguagem. É 'ego' que diz ego. Encontramos aí o fundamento da 'subjetividade' que se determina pelo status linguístico da pessoa".

Outras ciências e outras teorias, tais como a fenomenologia e a psicologia a que Benveniste (2015) faz menção, tomaram como referência de seus pressupostos a constituição do sujeito. Em seus trabalhos, porém, Benveniste aproxima a faculdade da linguagem da formação simbólica da consciência, dado que se revela diante da natureza imaterial de que são resultantes a língua e seus constituintes. A linguagem atravessa o homem e suas relações com outros homens, na medida em que, por meio da linguagem, ele se assume sujeito diante de outro sujeito. É dessa maneira que Benveniste concebe todas as línguas enquanto linguagem, uma vez que a subjetividade e a intersubjetividade são atributos do fenômeno de todas elas.

Nesse sentido, a constituição da natureza dos pronomes a partir da noção de pessoa ganha importância na teoria de Benveniste, pois é por meio dos pronomes que se identificam os constituintes axiais que permitem o fenômeno da enunciação. O Eu perfaz o trajeto da manifestação da língua por meio do constituinte linguístico eu, que se assume na instância do discurso, pressupondo o tu na enunciação. Desse modo, a produção dos enunciados só se faz por meio da relação necessária entre eu e tu.

65 Flores (2013) divide a obra de Benveniste em três momentos distintos de sua teoria: o primeiro diz respeito à questão da pessoa e da não-pessoa; o segundo corresponde a distinção entre a semiótica e a semântica do uso da língua; o terceiro discute a noção do aparelho formal da enunciação.

66 Problemas explorados nos capítulos intitulados "Da subjetividade da linguagem" e "A natureza dos pronomes" do livro Princípios de Linguística Geral. 
- Teoria enunciativa de Benveniste e semiótica discursiva: contribuições para a análise de textos

A partir dessa relação estabelecida entre eu e $t u$, Benveniste estabelece que o ele corresponde à não-pessoa, uma vez que nele não reside a troca intercambiável e necessária presente em eu-tu, que permite o fenômeno da enunciação. Em Estrutura das relações de pessoa no verbo, Benveniste (2015, p. 252) diferencia a terceira pessoa do caráter intrínseco entre "pessoa" e "sujeito", em que o ele aparece nas formas flexionais dos verbos em terceira pessoa para tratar de fenômenos, cuja produção não se reporta a um "agente".

Não sendo uma forma marcada da correlação entre pessoas, a não-pessoa é o único modo de enunciação possível para as instâncias de discurso que não devam remeter a si mesmas (BENVENISTE, 2015). É por essa razão, segundo o autor, que a não-pessoa pode combinar-se com qualquer referência de objeto, comportar um número bastante grande de variantes pronominais ou demonstrativas e não ser compatível com o paradigma do aqui e do agora.

Essas considerações de Benveniste explicam, por exemplo, o fenômeno da dêixis, responsável pela retomada de elementos na instância da enunciação a partir da perspectiva dos sujeitos locutor e alocutário, ao mesmo tempo em que o fenômeno da anáfora e o da catáfora retomam elementos intratextuais ao longo dos enunciados.

De acordo com Greimas e Courtés (2008, p. 166), a perspectiva de Benveniste para o tratamento da enunciação toma esse conceito enquanto uma "estrutura não-linguística (referencial) que subtende à comunicação linguística", uma vez que está voltada para a situação de comunicação. Essas considerações de Benveniste foram importantes para a semiótica refletir a presença do sujeito em seu modelo teórico-metodológico, que estava, até então, apagada. A importância da visão benvenistiana sobre a produção da linguagem vai ser responsável pela organização da metodologia da semiótica, pois fornecerá bases mais sólidas para a consecução do nível discursivo do percurso gerativo de sentido. Ocorre, porém, que, na visão da semiótica pensada por Greimas e seu grupo de pesquisadores, a enunciação deve ser entendida, distintamente da de Benveniste, como "uma instância linguística, logicamente pressuposta pela própria existência do enunciado (que dela contém traços e marcas)" (GREIMAS; COURTÉS: 2008, p. 166). Isso decorre do fato de que, "sendo o enunciado considerado o resultado alcançado pela enunciação, esta aparece como a instância de mediação, que assegura a colocação em enunciado-discurso das virtualidades da língua" (GREIMAS; COURTÉS, 2008, p. 166).

A partir da apresentação dos conceitos elementares e norteadores da visão sobre a enunciação em Benveniste, cabe examinar, no próximo item, os princípios da semiótica discursiva com o objetivo de explicitar o tratamento proposto por ela para a abordagem da enunciação no discurso para, posteriormente, examinarmos alguns elementos desse processo num texto específico. 


\section{Semiótica discursiva oriunda dos trabalhos de Algirdas Julien Greimas}

Tendo sido publicado em 1966 por Greimas, Sémantique Structurale deu início a uma série de reflexões sobre a perspectiva dos estudos semióticos que se ramificaram em várias outras vertentes voltadas não só para a questão da linguagem verbal, mas também para a de diversas outras linguagens, a partir da natureza semiótica de seus objetos em particular.

Em seu início, por sua filiação ao projeto estruturalista que se preocupava com a descrição formal da constituição da significação, o modelo semiótico pensado por Greimas não se preocupou com a manifestação da subjetividade e procurou desenvolver o projeto gerativo da constituição do discurso, desenvolvendo, de forma mais destacada, os elementos dos níveis fundamental e narrativo, deixando o nível discursivo para ser desenvolvido de forma mais completa posteriormente.

Ao se voltar para os elementos constituintes do nível discursivo de sua proposta para o percurso gerativo de sentido, Greimas e seu grupo debruçaram-se sobre os estudos empreendidos por Benveniste e, a partir desse fato, inseriram a questão da subjetividade no modelo semiótico em desenvolvimento, ressaltando que esse sujeito era uma instância de linguagem projetada pela enunciação e não correspondia exatamente ao sujeito em carne e osso presente, por exemplo, no processo interlocutivo de uma relação dialógica.

Tanto a semiótica quanto a teoria enunciativa de Benveniste, por sua vez, exploram o aspecto do uso deixado de lado por Saussure em seu Curso de Linguística Geral. Seguindo a esteira de Saussure para explicar o funcionamento da linguagem em Benveniste, é possível observar neste último autor que o fenômeno da enunciação depende de um paradigma referente ao sistema, posto em uso no eixo sintagmático, em que o eu é eixo da engrenagem do seu aparelho formal, uma vez que a enunciação "é este colocar em funcionamento a língua por um ato individual de utilização. O discurso [...] é o ato mesmo de produzir um enunciado, e não o texto do enunciador, que é o nosso objeto" (BENVENISTE, 1989, p. 82).

O discurso, para Benveniste, é um processo gerenciado por essa relação do uso da linguagem que possibilita a significação. Nesse sentido, Benveniste postula que há dois aspectos a partir dos quais esse processo pode ser examinado: a realização vocal da língua, que é a mais perceptível e direta, seguida pelo seu mecanismo de produção. No entanto, era difícil à altura de sua abordagem sobre o aparelho formal da enunciação, pensar como o mecanismo de produção de sentido se formava em palavras e em que termos descrever a interação entre ambos, formando discursos. O que ele aponta, porém, é a pista de que a enunciação, que "supõe a conversão individual da língua em discurso", pudesse conduzir ao que ele chamaria de "teoria do signo" e de "análise da significância" (BENVENISTE, 1989, p. 82-83). Dessa forma, o sentido estaria então definido em um 
- Teoria enunciativa de Benveniste e semiótica discursiva: contribuições para a análise de textos

quadro de realização, a partir de métodos que identificassem o percurso de sua formação e de sua manifestação. Saberíamos então, mais tarde que uma semiótica discursiva estaria por vir com Greimas e seu percurso gerativo de sentido.

O percurso gerativo de sentido permite, por meio da semiose que é resultante da manifestação dos enunciados, rever o trajeto da significação. O percurso é compreendido, assim, como um simulacro metodológico das abstrações que o leitor faz ao ler o texto (BARROS, 1990). Segundo Greimas, que se vale, conforme já afirmamos anteriormente, das contribuições de Benveniste para pensar o nível discursivo do percurso gerativo do sentido proposto por sua semiótica, o texto é o produto do processo discursivo, em que a significação corresponde a um construto produzido em diferentes instâncias. Nesse sentido, o texto corresponde ao objeto central das propostas da semiótica discursiva, uma vez que, tanto para a semiótica quanto para a teoria enunciativa de Benveniste, todo enunciado consiste na manifestação resultante do uso do aparelho formal da linguagem, cujo sentido é resultante de seu uso individual e cada vez único.

O percurso gerativo do sentido, conforme já apontado, é constituído por três níveis, o fundamental, o narrativo e o discursivo, entendidos esses patamares como aqueles que vão do nível mais abstrato ao mais concreto. O nível fundamental é mais constante em relação ao nível narrativo que, por sua vez, também o é em relação ao nível discursivo. Este último constitui-se na realização do conteúdo manifestado no texto, razão pela qual temos a singularidade cada vez única dos conteúdos expressos no último nível.

A enunciação é uma instância de mediação que assegura a discursivização da língua, que permite a passagem da competência à perfórmance, das estruturas semióticas virtuais às estruturas realizadas sob forma de discurso. Percorrendo as marcas deixadas nos enunciados, chegamos à instância da enunciação deles pressuposta. O enunciado frequentemente comporta elementos que remetem à instância da enunciação, tal como demonstrativos, pronomes pessoais, adjetivos e advérbios, dêiticos espaciais e temporais que podem ser orientados por duas diferentes formas de manifestação. Quando forem explicitados, produzem uma debreagem enunciativa; quando estiverem apagados, uma debreagem enunciva. Pode ainda ocorrer o processo de neutralização dos elementos dêiticos, o que corresponderá, segundo a teoria semiótica discursiva, à embreagem, que também pode ser enunciativa ou enunciva.

Uma vez que nos textos enunciativos e enuncivos são observados os mecanismos de instauração de pessoa, de espaço e de tempo no enunciado, sempre que esse discurso manifesta as instâncias do eu, do aqui e do agora ocorre a chamada debreagem enunciativa, enquanto a debreagem enunciva é aquela que remete às instâncias do nãoeu (ele), do não-aqui (lá) e do não-agora (então). Quanto à embreagem, na medida em que consiste no efeito de retorno à enunciação, produzido pela neutralização das categorias de pessoa, espaço e tempo, pode ocorrer o uso do ele no lugar do eu, do lá no lugar do 
aqui, do então no lugar do agora, ou vice-versa, o que irá corresponder à embreagem enunciativa ou enunciva.

Descritos, de modo geral, os preceitos fundamentais da teoria enunciativa de Benveniste e a maneira como a semiótica discursiva incorpora a questão no nível discursivo de seu percurso gerativo do sentido, podemos passar ao tópico seguinte, em que procuraremos esboçar a análise de um texto com base na descrição teórica aqui delineada.

\section{Análise da Matéria Ma France à moi!}

Tomemos o relato abaixo reproduzido da subseção Ma France à moi!, da revista Gazelle, número 56, traduzido por nós para o português. Trata-se de uma matéria sobre a identidade franco-magrebina, com relatos de pessoas que vêm dos países do norte da África, ou de franceses que têm ascendência marroquina, argelina e tunisiana.

Aya, 34 anos, doméstica, duas crianças, em Abu Dhabi: "Minha França é aquela da periferia do sul de Paris, de onde tenho boas lembranças de infância, em Grigny, ou em Savigny-sur-Orge. Minha França é aquela onde minha mãe despreocupada nos deixava ir sozinhos buscar pão ou ir à biblioteca do bairro. Aquela onde nós quase não distinguíamos a origem ou a religião de nossos amigos, aquela onde tínhamos bons professores, onde a gente passava nosso tempo brincando e rindo. Era uma França onde tínhamos muitos francos nos nossos cofrinhos. 'Sinto saudade de você!' Dessa França que, infelizmente, penso nunca mais encontrarei. Há dois anos, vivo nos Emirados Árabes, em Abu Dhabi. Não me vejo educando minhas duas crianças nessa França que se degradou enormemente nesses últimos anos e onde a liberdade de culto é uma ilusão. Aqui, tenho a impressão de reencontrar certos valores que conheci mais jovem: o respeito aos outros, a tolerância, a solidariedade. Aqui, a vida é bem melhor, longe do metro/boulot/dodo. Temos tempo para viver, ver nossas crianças crescerem, oferecer a elas uma boa qualidade de vida, e tudo isso sob o sol. Mas o que aprecio antes de tudo é o casamento entre o Oriente e o Ocidente. Aqui, todas as confissões têm representatividade, cada um é livre para praticar seu culto, respeitando a tradição muçulmana." (GAZELLE, 2014, p. 74 , tradução nossa) ${ }^{67}$

O relato acima é de uma mãe de ascendência árabe, que vivera os tempos de infância na França, mais especificamente nas comunas de Grigny e de Savigny-sur-Orge.

67 Aya, 34 ans, mère au foyer, mariée, 2 enfants, Abu Dhabi. Ma France, ma très chère France, c'est celle dans la banlieue sud de Paris où j'ai des très bons souvenirs d'enfance à Grigny ou à Savigny-sur-Orge. Ma France, celle où ma maman insouciante nous laissait seuls, aller chercher le pain ou aller à la bibliothèque du quartier. Celle où nous ne distinguions guère l'origine ou la religion des nos amis, celle où nous avions de très bons profs. Où 
- Teoria enunciativa de Benveniste e semiótica discursiva: contribuições para a análise de textos

A tradição pede que façamos o percurso canônico dos níveis, ou seja, o percurso que vai do nível fundamental e narrativo, os mais abstratos, ao nível discursivo, mais concreto. No entanto, a análise pode começar em qualquer um dos níveis ou mesmo ficar em apenas um deles. No nosso caso, começaremos pelo nível discursivo do percurso.

Todos os níveis do percurso gerativo do sentido proposto pela semiótica discursiva possuem uma sintaxe e uma semântica que se complementam. Aquela corresponde ao conjunto de mecanismos que ordena os conteúdos; esta, aos conteúdos que são investidos nos arranjos sintáticos. Na sintaxe e na semântica discursivas, o sujeito faz uma série de escolhas de pessoa, de tempo e de espaço, revestidas de figuras e de temas. Daí o nível discursivo ser complexo, pois se trata de uma variância dos níveis narrativo e fundamental, que são, por sua vez, mais constantes e abstratos em relação àquele nível.

No texto intitulado As relações de tempo no verbo francês (1995), Benveniste faz uma distinção entre o uso do passé simple e do passé composé em textos que remetem a uma anterioridade do nível da história e do discurso. No texto que traduzimos, não é possível localizar tal distinção, posto que, no português, não há marcas do anterior perfeito e do anterior aoristo, que Benveniste destaca e que atribui como pertinente à estrutura do verbo francês. Sendo o relato de Aya uma transposição do francês para o português, o tempo do verbo em francês remete à instância da enunciação própria do passé composé, que denota o uso da oralidade, revelando marcas da enunciação no enunciado.

Ainda que pelo tempo verbal no português não seja possível identificar esse aspecto enunciativo, os conceitos de debreagem e embreagem permitem, no entanto, realizar o percurso que chega à enunciação enunciada por meio de outras marcas que os interlocutores do discurso deixam ao enunciar.

Dessa forma, no texto que transcrevemos, temos a princípio uma debreagem enunciativa de pessoa, devido à recorrência de adjetivos pronominais que marcam a presença do sujeito no enunciado. Essa debreagem instaura, por sua vez, a debreagem enunciva de tempo e de espaço, graças às inflexões do verbo no imperfeito e no pretérito perfeito, criando o efeito de um passado distante. A categoria de espaço, que tem como referente a França, é resgatada anaforicamente pelo pronome "aquela", que, quando retoma o referente anterior do texto, agrega-lhe mais atributos.

I'on passait notre temps à jouer et rire. Une France où nous avions beaucoup de Francs dans nos tirelires. «Tu me manques ! »Cette France que, malheureusement, je pense ne jamais retrouver. Depuis deux ans, je vis aux Emirats Arabes Unis, à Abu Dhabi. Je ne me voyais pas éduquer mes deux enfants dans cette France qui c'est énormément dégradée ces derniers années et où la liberté de culte est un leurre. Ici, j’ai comme la impression de retrouver certains valeurs que j'ai connues plus jeune : le respect des autres, la tolérance, la solidarité. Ici, la vie est bien meilleure, loin du métro/boulot/dodo. On prend le temps de vivre, de voir ses enfants grandir, de leur offrir une très bonne qualité de vie, et tout ça sous le soleil. Mais ce que j'ai apprécie avant tout, c'est le mariage entre l'Orient et l'Occident. Ici, toutes les confessions sont représentées, chacun est libre de pratiquer son culte, tout en respectant la tradition musulmane. 
Temos, assim, a presença dos pronomes possessivos e dos verbos em primeira pessoa que revestem de subjetividade a França dos primeiros tempos da infância do sujeito Aya, ator da enunciação. A França é o lugar particular dessa infância, que a encerra em um passado distante, evocado, no entanto, na presente instância da enunciação, e que cria, ao mesmo tempo, uma dada cena enunciativa, por meio da potência da língua em criar universos abstratos com base no vivido, recriado pela enunciação.

Após a partida de Aya, instaura-se uma outra cena enunciativa, em que são engendradas as debreagens enunciativas de tempo e espaço. É quando temos uma guinada do enuncivo ao enunciativo, perpetrados pelos demonstrativos "aquele" e "esse". Por meio dessas marcas da língua, Aya aproxima a França do ponto de referência em que ela se situa, processo que a debreagem enunciativa de espaço permite instaurar. Essa França, diferente daquela de sua infância, é o país no qual ela não quer que suas crianças sejam educadas. Tal diferença é reforçada pelas inflexões dos verbos no presente do indicativo.

Após relatar sua experiência de infância, o sujeito enunciador remete a cena ao aqui do seu ponto de referência. Temos pois uma gradação que vai da debreagem enunciva à enunciativa, quando Aya diz: "Aqui, a vida é bem melhor, longe do metro/ boulot/dodo. Temos tempo para viver, ver nossas crianças crescerem, oferecer a elas uma boa qualidade de vida, e tudo isso sob o sol"68. O aqui remete ao espaço concomitante do sujeito locutor, em que os verbos no presente, flexionados na primeira pessoa do plural, predominam. Temos então uma predominância actorial, temporal e espacial que instauram a debreagem enunciativa.

Até aqui tratamos tão somente da sintaxe do nível discursivo, visto que nesse aspecto residem questões teóricas caras para o intuito deste artigo. Retomar todos os patamares dos níveis do percurso gerativo requereria passar o texto analisado pelo crivo da semiótica discursiva, tangenciando a teoria enunciativa de Benveniste. Podemos, no entanto, fazer uma análise resumida do texto, abordando brevemente todos os níveis, sem ir além de nosso objetivo.

Na semântica do nível discursivo são identificados temas e figuras, cujo conjunto garante a figurativização e a tematização. Na primeira, as figuras do conteúdo recobrem os percursos temáticos abstratos, revestindo-os de elementos sensoriais retirados do "mundo natural". Já a tematização garante à leitura do texto a depreensão de traços semânticos ou semas que implicam valores abstratos organizados em percursos. Aya é o enunciador que reveste a França como o espaço em que circulam o pão, a biblioteca, a escola com bons professores, os francos no cofrinho. Esse processo de constituição das figuras é responsável por estabelecer o "contrato de veridicção", ou contrato fiduciário, entre o enunciador e o

68 Ici, la vie est bien meilleure, loin du métro/boulot/dodo. On prend le temps de vivre, de voir ses enfants grandir, de leur offrir une très bonne qualité de vie, et tout ça sous le soleil. 
- Teoria enunciativa de Benveniste e semiótica discursiva: contribuições para a análise de textos

enunciatário, estabelecido pelo fazer-crer e pelo crer. Esse contrato depende justamente dos liames estabelecidos entre as figuras referentes ao mundo, retomadas no discurso. Ora, o fato de Aya ser uma muçulmana, nascida e criada na França, e de ter encontrado, posteriormente, segurança em Abu Dhabi, que correspondem a locais ligados à realidade do mundo, produz o efeito de realidade no texto enunciado.

Além disso, a própria composição do texto relato, que instala o ator Aya no enunciado, garante esse efeito, visto que o sujeito enunciador delega a ele voz em primeira pessoa, como se o ator instalado dialogasse com o leitor diretamente. É o enunciador da revista Gazelle que, por sua vez, seleciona o ator e sua voz, aproximando o leitor/enunciatário da imagem de Aya e dos valores por ela transmitidos. Aya não só é um ator do enunciado, mas, sendo exposta, reflete o público-alvo da revista: a mulher muçulmana, de ascendência magrebina, que procura seu lugar em um mundo cindido entre o Oriente e o Ocidente, com prevalência de valores deste último. Estabelece-se um contrato fiduciário pressuposto entre enunciador e enunciatário, que subsume uma estratégia editorial que dialoga com a identidade do público-alvo a quem a revista visa, identidade essa reforçada pelo efeito de proximidade das marcas da enunciação deixadas no enunciado.

As características desse percurso são ancoradas pela sintaxe e pela semântica do nível narrativo. Na sintaxe desse nível, pretende-se tecer um simulacro do percurso do fazer do homem que transforma o mundo por meio de um aparato metodológico próprio a esse nível. Assim, temos enunciados de estado em que o sujeito ator do enunciado Aya encontra-se em junção com os objetos valor "pão", "religião", "bons professores" e "francos". Em outro momento, encontramos enunciados de fazer, em que "essa França" é sujeito que transforma o sujeito "Aya", que é privado dos objetos-valor de sua infância. Aqui o sujeito se encontra em disjunção com tais objetos-valor, que só lhe são devolvidos pela instalação de um outro sujeito, "Abu Dhabi". Este devolve não somente a Aya, mas a seus filhos, os objetos-valor da educação, da qualidade de vida, do casamento entre Oriente e Ocidente e do respeito à tradição muçulmana. Como se pode ver, esse nível estabelece programas narrativos dos sujeitos de fazer e de estado, em que França e Abu Dhabi são, por sua vez, os sujeitos destinadores de objetos aos destinatários do percurso narrativo do sujeito Aya.

De acordo com Barros (1990, p. 42), na semântica narrativa, os elementos semânticos decorrentes da modalização e das paixões do sujeito são selecionados e relacionados. Identificamos a modalização do fazer geralmente com o destinador, que transforma o sujeito-destinatário do enunciado, fazendo-fazer, isto é, fazendo-o agir de acordo com os objetos modais que lhe são doados. O sujeito, por sua vez, transforma-se de acordo com as modalidades do querer, do saber, do dever e do poder. 
Tomemos por exemplo a última parte do relato, em que Aya se diz residente em Abu Dhabi. Essa cidade, em comparação com a França que ela evoca, é aquela que permite viver em consonância com os valores da liberdade de culto, com a tolerância e com o sincretismo cultural oriental e ocidental. Esses valores para ela são objetos-valor que subsumem objetos modais, por exemplo, quanto à sua vontade de criar as crianças. Enquanto mãe, ela é competente, isto é, ela sabe-fazer. Somente com a sanção do destinador Abu Dhabi é que ela pode-fazer, ou seja, que ela pode cuidar de seus filhos. $\mathrm{O}$ destinador aqui permite que Aya passe da competência à performance - ela sabe cuidar e ela pode cuidar.

As paixões, no entanto, são decorrentes do arranjo modal e das estruturas narrativas que caracterizam e denominam os estados de alma. Sem que percorramos os programas narrativos, podemos inferir que a frustração por parte de Aya decorre do fato de acreditar que os objetos-valor da liberdade e da tolerância na França são privados dela e de seus filhos. Nessa França, diz ela, "a liberdade é uma ilusão".

Por fim, chegamos ao nível elementar do percurso, em que são definidas as oposições semânticas. Essas oposições baseiam-se em relações categoriais de euforia e disforia. Aqui é onde se dão os eixos da contradição, da contrariedade e da complementaridade que arquitetam o quadrado semiótico. No relato de Aya, observamos que a liberdade é euforizada na sua infância. Enquanto mãe muçulmana, a liberdade só é possível em Abu Dhabi. Da França aos Emirados Árabes Unidos, da infância ao crescimento, observamos uma micro-narrativa, em que o sujeito Aya sai do eixo da dominação, passa pela não-dominação, culminando na liberdade. A partir do momento em que o enunciado é produzido pelo sujeito, portanto, a França assume um valor disfórico, negativo, enquanto Abu Dhabi, um valor eufórico, positivo. Um corresponde à projeção da opressão; o outro, ao da liberdade.

O percurso gerativo de sentido garante, enquanto simulacro metodológico, uma leitura interpretativa fechada e imanente às propriedades internas do texto. A partir delas e de seu agenciamento nos diferentes níveis em que se organiza o percurso gerativo de sentido, podemos fazer escolhas temáticas que se depreendem desse processo. Um dos temas é o do exílio da pátria. No poema de Gonçalves Dias, Canção do Exílio, o eu-lírico exilado enaltece as belezas naturais de sua terra natal, impregnando-a de subjetividade, no jogo entre o lá da pátria amada, e o cá do exílio. Aya faz o mesmo ao euforizar os elementos da França de sua infância, mas disforizando-os, em seguida, quando remete ao momento presente. Assim, tanto no poema quanto no relato temos valores melhorativos ou depreciativos da marca do sujeito da enunciação sobre seus referentes da debreagem enunciva temporal e espacial.

Levando em consideração a leitura que fizemos, podemos enfim comparar o tema a outros textos extrínsecos, dando suporte à leitura temática. O exílio é uma realidade no contexto familiar muçulmano, em que as famílias entram em países europeus e saem 
- Teoria enunciativa de Benveniste e semiótica discursiva: contribuições para a análise de textos

deles sob o estigma da imigração e do não pertencimento ao território que resiste em acolhê-los. O relato de Aya remete a esforços de imigrantes muçulmanos que tentam se adaptar ao contexto global ocidental, sem abandonar os valores da tradição islâmica, como o descreve Tariq Ramadan (2015, p. 352, tradução nossa):

Até agora, no Ocidente, os muçulmanos que gostariam de permanecer fiéis a seus princípios estão evidentemente "em pane", condenados a se trair ou a se marginalizar. Voluntariamente ou não, eles poderão ser somente auxiliados no plano econômico e financeiro. Eles, cuja responsabilidade primeira estaria no coração do sistema ao proporem "outra coisa", veem-se constrangidos à demissão, ou a sonhar, como alguns afirmam, com a iminente implosão do sistema "por si mesmo", "do interior". ${ }^{9}$

É importante ainda considerar uma questão determinante para o processo de compreensão do texto examinado aqui neste trabalho. Trata-se do fato de ele estar inserido numa revista cujo enunciatário consiste na projeção da imagem de um sujeito franco-magrebino muçulmano. O fato de Aya, no texto aqui destacado, opor a França aos Emirados Árabes Unidos, caracterizando o primeiro espaço como o da opressão e o segundo o da liberdade, reflete o pensamento desse sujeito a quem a revista se dirige e, ao mesmo tempo, ao do próprio enunciador. Para tanto, torna-se necessário observar como se constitui esse suporte de comunicação que corresponde à revista.

Gazelle caracteriza-se como uma revista feminina de variedades que inclui moda, culinária, comportamento, etc., da mesma forma que outras revistas existentes, tal como a francesa Elle. Diferentemente desta que se volta para a mulher ocidental, europeia ou americana, Gazelle identifica-se com um público feminino específico, fato identificado pelo próprio subtítulo da revista, que aparece acima de seu nome em sua capa: "A revista da mulher magrebina"70 (conforme anexo 1).

Tendo em vista a colonização francesa ocorrida na África, durante os séculos XIX e XX, principalmente na Argélia e na Tunísia, que fazem parte da região do Magrebe, houve uma migração de parte dessa população para o território francês, principalmente para as comunas em volta de Paris. Em decorrência dessa afluência de imigrantes, a França viveu, e ainda vive, um conturbado processo político, que se intensifica com o choque cultural, tendo em vista o fato de que os povos magrebinos seguem a orientação religiosa islâmica, que mantém uma relação estreita com o regime político, distinta da tradição religiosa

69 A ce jour, en Occident, les musulmans qui aimeraient rester fidèles à leurs principes sont clairement 'en panne' : condamnés à se trahir ou à se marginaliser. A terme, volontairement ou non, ils ne pourront être, sur le plan économique ou financier, que des assistés : eux dont responsabilité première était, au cœur du système, de proposer 'autre chose' se voient contraints à la démission ou à rêver, comme certains l'affirment en se rassurant, l'imminente implosion du système, "par lui-même », « de l'intérieur ».

70 Le magazine de la femme maghrébine 
católica do povo francês, que opta por uma condução laica para a formulação de política social. Nesse sentido, a proposta da Gazelle está voltada para um problema de identidade do povo magrebino que vive em território francês e que se sente marginalizado, uma vez que seus hábitos e sua religião não são aceitos pela população e pela política francesa. Em decorrência disso, muitos acabam voltando para seu local de origem, como é o caso da Aya, a enunciadora do texto aqui examinado. A afirmação do discurso da revista é, assim, a construção da identidade magrebina.

O que se pretende afirmar, portanto, é que o sujeito enunciador do texto destacado enuncia o ponto de vista da revista e do público a que ela se dirige. Assim, por trás da voz de um enunciador específico, o caso do sujeito Aya, no texto em exame, há um outro enunciador que fala, qual seja, a editoria de Gazelle, que, por sua vez, coloca-se como porta-voz da identidade do povo magrebino em relação ao povo francês.

Cabe examinar também, para identificar de forma mais precisa o enunciado, que ele está inserido em um espaço específico no todo que compõe o enunciado da revista. O texto de Aya aqui examinado aparece em uma subseção da revista, intitulada Ma France à moi!, que, traduzido de forma livre, não literal, significaria algo próximo a "A imagem que tenho da França". Essa subseção está no interior de um conjunto de textos que compõem a seção intitulada Bien être et psycho (Bem-estar e psicologia). Assim, o número da revisa Gazelle do qual foi selecionado o texto para análise é composto por seis seções, intituladas da seguinte forma: Actus; Mode \& Beauté; Bien être et psycho; Amour et mariage; Grossesse \& enfants; Loisir \& découverte.

A subseção Ma France à moi!, que se inicia na página 74 da revista (conforme anexo 2), tem como foto de fundo duas modelos com sorrisos estampados em seus rostos colados um ao outro, o que denota a intensificação da proximidade, em que se podem identificar os fenótipos da mulher francesa e da mulher magrebina. A garota francesa, do lado esquerdo da página, tem a bandeira da Argélia pintada no lado direito de seu rosto; a garota magrebina, do lado direito, tem a bandeira da França pintada no lado esquerdo de seu rosto. Uma vez mais se pode identificar, na imagem das duas modelos que se tocam, uma mensagem de harmonia e de identidade, em que não se marca a distinção entre o nacional e o estrangeiro, qual seja, uma oposição entre o francês e o magrebino.

O texto de Aya aparece na parte inferior da página 74, mas não é o único a tratar do mesmo tema, pois é seguido por mais outros três. O segundo e o terceiro estão lado a lado na parte superior da página 75 e o quarto, na parte inferior. Entre os dois primeiros e o último aparecem em destaque, em cor azul, várias frases atribuídas a pessoas não identificadas que reforçam a imagem particular de cada um sobre a França.

Dentre os quatro textos reproduzidos nas páginas 74 e 75 da revista, o de Aya e o de Farid reportam-se a uma França positiva no passado e negativa no presente; o de Emel e o de Assia referem-se a uma França positiva no presente. Nesse sentido, o que 
- Teoria enunciativa de Benveniste e semiótica discursiva: contribuições para a análise de textos

se observa é que a subseção Ma France à moi! é composta por enunciadores jovens (2 com 33 e 2 com 34 anos), do sexo masculino (1) e do feminino (3), em que as visões da França são positivas no presente da enunciação e negativas no passado (2) e positivas no presente da enunciação (2). A simetria, portanto, é reforçada tanto do ponto de vista das informações das características das enunciações verbais quanto da enunciação visual.

A informação final, apreendida da relação entre o conteúdo do enunciado do texto de Aya, inserido na subseção Ma France à moi!, que, por sua vez, está inserida no contexto do discurso da revista Gazelle, remete à tensão entre a França e os povos do Magrebe, mas isso é apresentado de uma forma distensa que apaga o confronto, isto é, mesmo quando há uma crítica à sociedade francesa, ela é amenizada por um ponto de vista positivo. Assim, tanto nos textos de Aya quanto no de Farid, a França é negativa no momento presente da enunciação, mas positiva no momento passado, qual seja, no período de infância em que eles lá viveram. Dessa forma, a tendência à harmonização ressaltada pelo discurso da revista Gazelle está voltada mais para a identificação do que para a diferença, isto é, embora afirme a identidade do povo magrebino, aproxima-o do povo francês, como se estivesse ressaltando o pertencimento do primeiro ao espaço do segundo. Essa é, então, a voz do enunciador-editor da revista.

\section{Conclusão}

Este trabalho procurou identificar o lugar das teorias enunciativas na linguística inaugurada pelo Curso de Linguística Geral. Pudemos constatar que a teoria enunciativa de Benveniste, bem como as teorias que tomam emprestadas suas contribuições, têm lugar nos estudos linguísticos que preveem a língua na sua atualização, ou na instância mesma do discurso, de onde seu programa teórico origina-se.

Em seguida, descrevemos alguns conceitos da teoria de Benveniste que impulsionaram a construção do nível discursivo do percurso gerativo de sentido proposto pela semiótica discursiva originária dos trabalhos de Greimas e de seu grupo, cujo procedimento sintático básico se constitui por meio dos conceitos de debreagem e de embreagem. Esses conceitos permitem descrever o percurso da significação a partir das marcas que os enunciadores deixam no enunciado, na instância da enunciação, processo que o aparelho formal da enunciação possibilita, revelando que cada enunciado resulta de um ato único e irrepetível.

Posteriormente, aplicamos tais conceitos ao texto de uma matéria da revista Franco Magrebina, Gazelle, intitulada Ma France à Moi!, a fim de demonstrar a contribuição interpretativa de tais conceitos para análise de textos de língua escrita. Por meio das noções de embreagem e de debreagem, observamos que é possível analisar os efeitos de subjetividade e de objetividade perpetrados no enunciado, segundo as projeções actoriais, temporais e espaciais presentes no aparelho formal da enunciação inscrito na língua. 
Por fim, é importante ressaltar nesta conclusão que o projeto de partir de um olhar sobre a contribuição dos estudos de Benveniste para o desenvolvimento da proposta teórico-metodológica da semiótica discursiva teve como finalidade última chegar à produção da análise de um texto escrito, evidenciando os componentes discursivos e suas relações com os diferentes níveis do percurso gerativo de sentido. O que se defende atualmente é que o modelo do percurso gerativo, ao invés de ser considerado ultrapassado, porque era interpretado de forma estanque, ganha mobilidade, de tal maneira que é possível perceber a interferência dos constituintes de cada nível, de forma dinâmica, tal como defendido por Fontanille (2007).

Além disso, o que se procurou evidenciar neste trabalho foi também a possibilidade de produzir uma análise que levasse em consideração o componente enunciativo de um texto não verbal. Não se pretendeu, porém, aprofundar a análise desse tipo de texto, porque isso demandaria mais espaço, o que aumentaria demasiadamente o tamanho deste trabalho. O objetivo foi mostrar a produtividade do modelo teórico-metodológico da semiótica discursiva para o tratamento tanto do texto verbal quando do não verbal, o que tem sido uma tônica das investigações dos estudiosos de semiótica no Brasil e no exterior atualmente. O que se pretende estabelecer são os elementos que constituem a linguagem do texto não verbal e a forma como são mobilizados durante a produção do texto. No caso da subseção da revista Gazelle aqui examinada, os elementos que devem ser observados para a elaboração do processo interpretativo dizem respeito àqueles por meio dos quais o texto é constituído. Inicialmente a página da revista é um texto plástico, planar, em que se articulam o plano da expressão e o plano do conteúdo, marcados por elementos categoriais, que correspondem aos componentes cromáticos, eidéticos e topológicos. Dessa forma, o que importa examinar durante o processo interpretativo é o valor que assumem as cores, as formas e os espaços em que esses elementos estão distribuídos na superfície do texto. Da mesma maneira que o elemento verbal, os componentes do texto visual pressupõem uma instância de enunciação nele projetada. Dessa forma, portanto, uma das tarefas prementes para os estudos semióticos consiste em reconstituir para o texto visual e para o verbo-visual os elementos responsáveis pela produção de seu sentido.

\section{Referências}

BARROS, D. L. P. de. Teoria semiótica do texto. São Paulo: Ática, 1990.

BENVENISTE, É. Problemas de Linguística Geral II. São Paulo: Campinas, 1989.

BENVENISTE, É. Problèmes de Linguistique Générale. France: Gallimard, 1966. 
- Teoria enunciativa de Benveniste e semiótica discursiva: contribuições para a análise de textos

COSTA e SILVA, C. L.; ENDRUWEIT, M. L. O oral e o escrito sob o viés enunciativo: reflexões metodológicas. ReVEL, v. 9, n. 16, p. 236-261, 2011. Disponível em: <http://www.revel.inf. br/files/artigos/revel 16 o oral e o escrito sob o vies enunciativo.pdf>. Acesso em: 8 out. 2018.

FIORIN, J. L. As astúcias da enunciação. As categorias de pessoa, espaço e tempo. São Paulo: Ática: 1996.

FIORIN, J. L. Elementos de análise do discurso. São Paulo: Contexto/EDUSP, 1989.

FIORIN, J. L. Enunciação e Semiótica. Letras no 33 Émile Benveniste: Interfaces Enunciação \& Discursos, p. 69-97, 2007. Disponível em: <https://periodicos.ufsm.br/letras/article/ view/11924/7345r>. Acesso em: 8 out. 2018.

FLORES, V. Introdução à Teoria de Benveniste. São Paulo: Parábola, 2013.

FONTANILLE, J. Semiótica do discurso. Tradução de Jean Cristtus Portela. São Paulo: Contexto, 2007.

GAZELLE. Marseille: Stardust Éditions, n. 56, 2014.

GREIMAS, A. J.; COURTÉS, J. Dicionário de Semiótica. São Paulo: Cultrix, 2008.

RAMADAN, T. Être occidental et musulman aujourd'hui. Paris: Presse du Châtelet, 2015.

SAUSSURE, F. Curso de Linguística Geral. São Paulo: Cultrix, 1980.

COMO CITAR ESTE ARTIGO: SARTINI POPOFF, Jorge Gabriel; CORTINA, Arnaldo. Teoria enunciativa de benveniste e semiótica discursiva: contribuições para a análise de textos. Revista do GEL, v. 15, n. 2, p. 98-116, 2018. Disponível em: https://revistadogel.gel.org.br/

DOI: http://dx.doi.org/10.21165/gel.v15i2.2120

Submetido em: 18/06/2018 | Aceito em: 04/10/2018 


\section{Anexo 1}

Capa da revista Gazelle, número 56 de março/abril de 2014

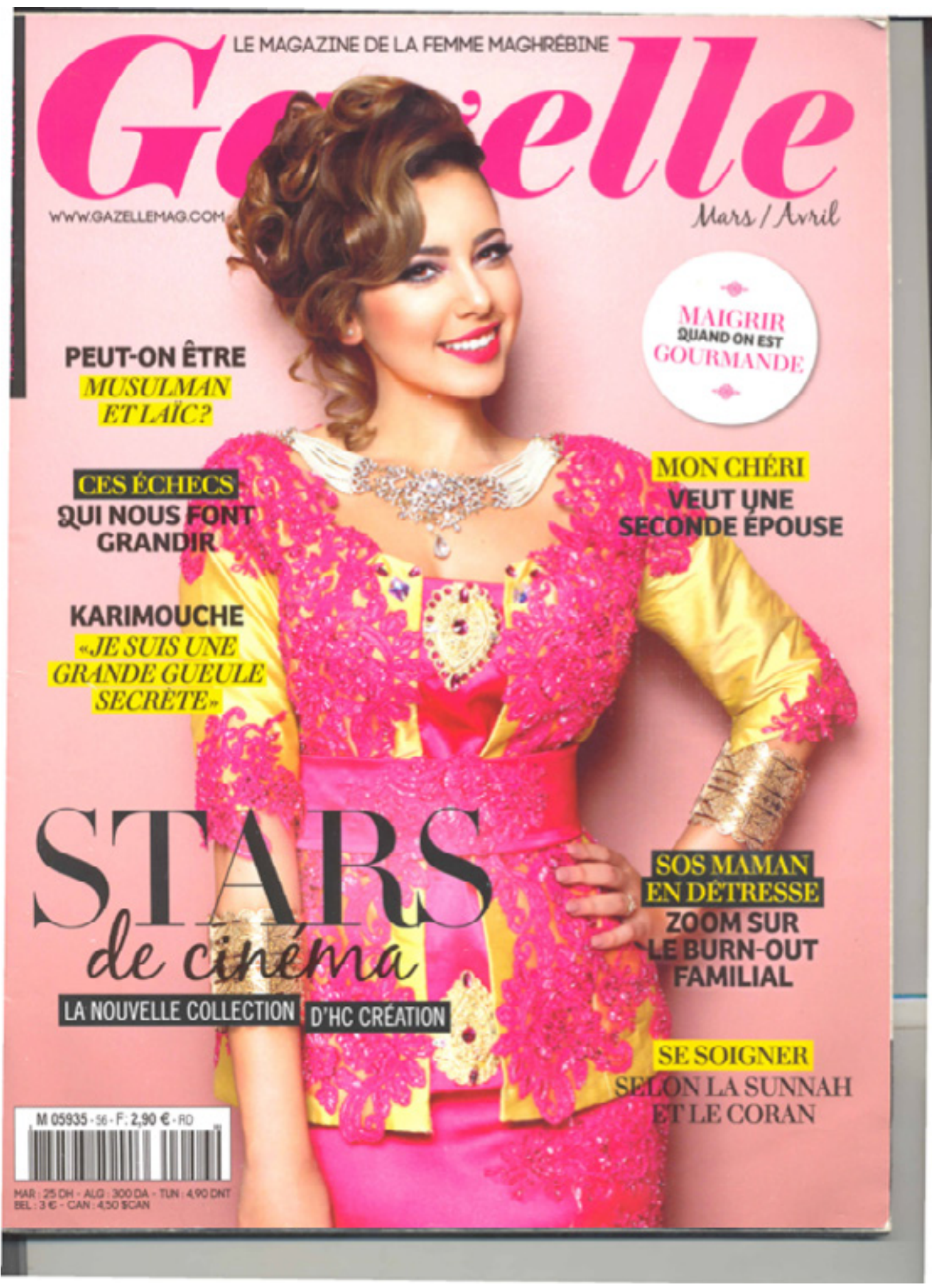


- Teoria enunciativa de Benveniste e semiótica discursiva: contribuições para a análise de textos

\section{Anexo 2}

Páginas 74 e 75 da revista Gazelle, número 56 de março/abril de 2014

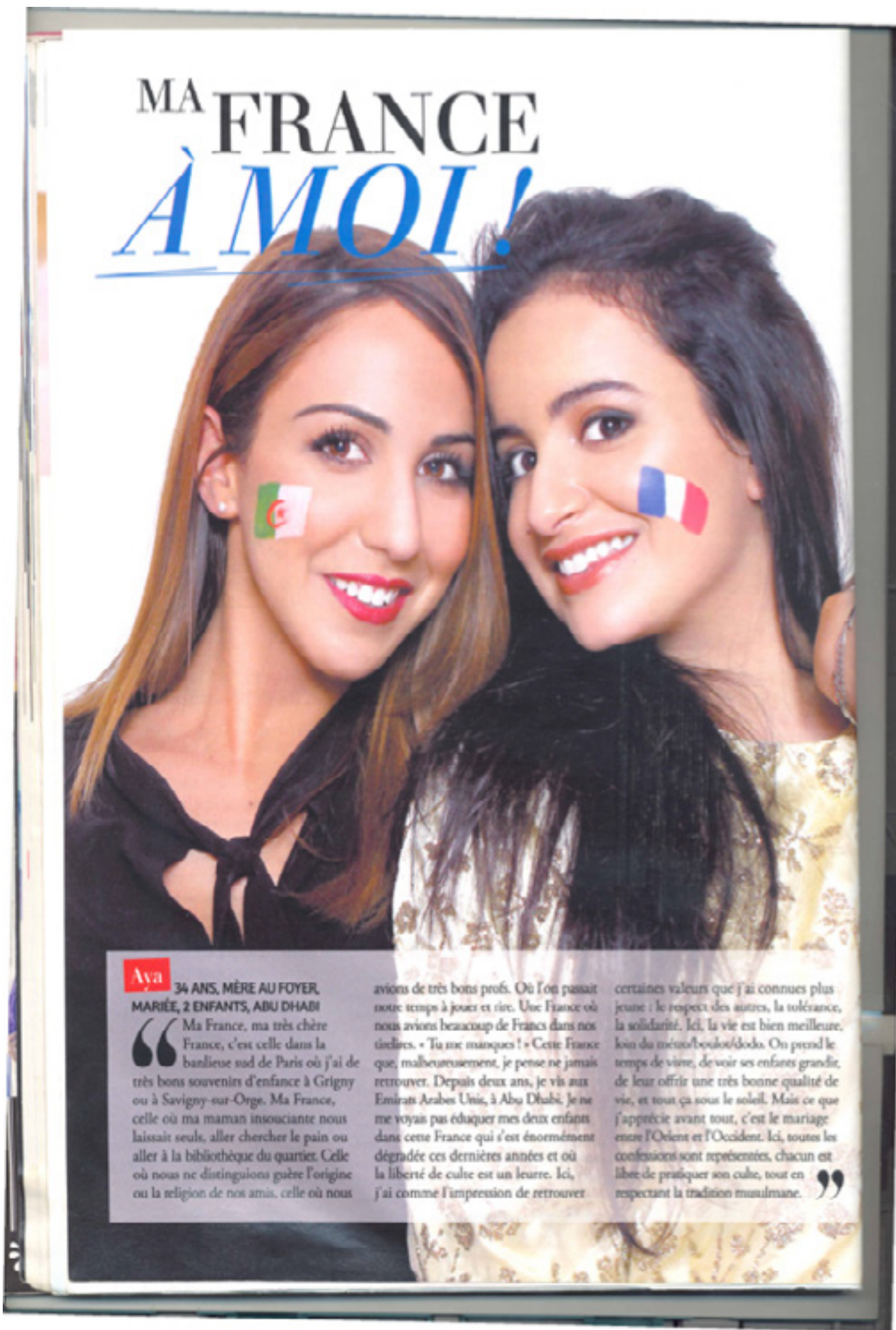




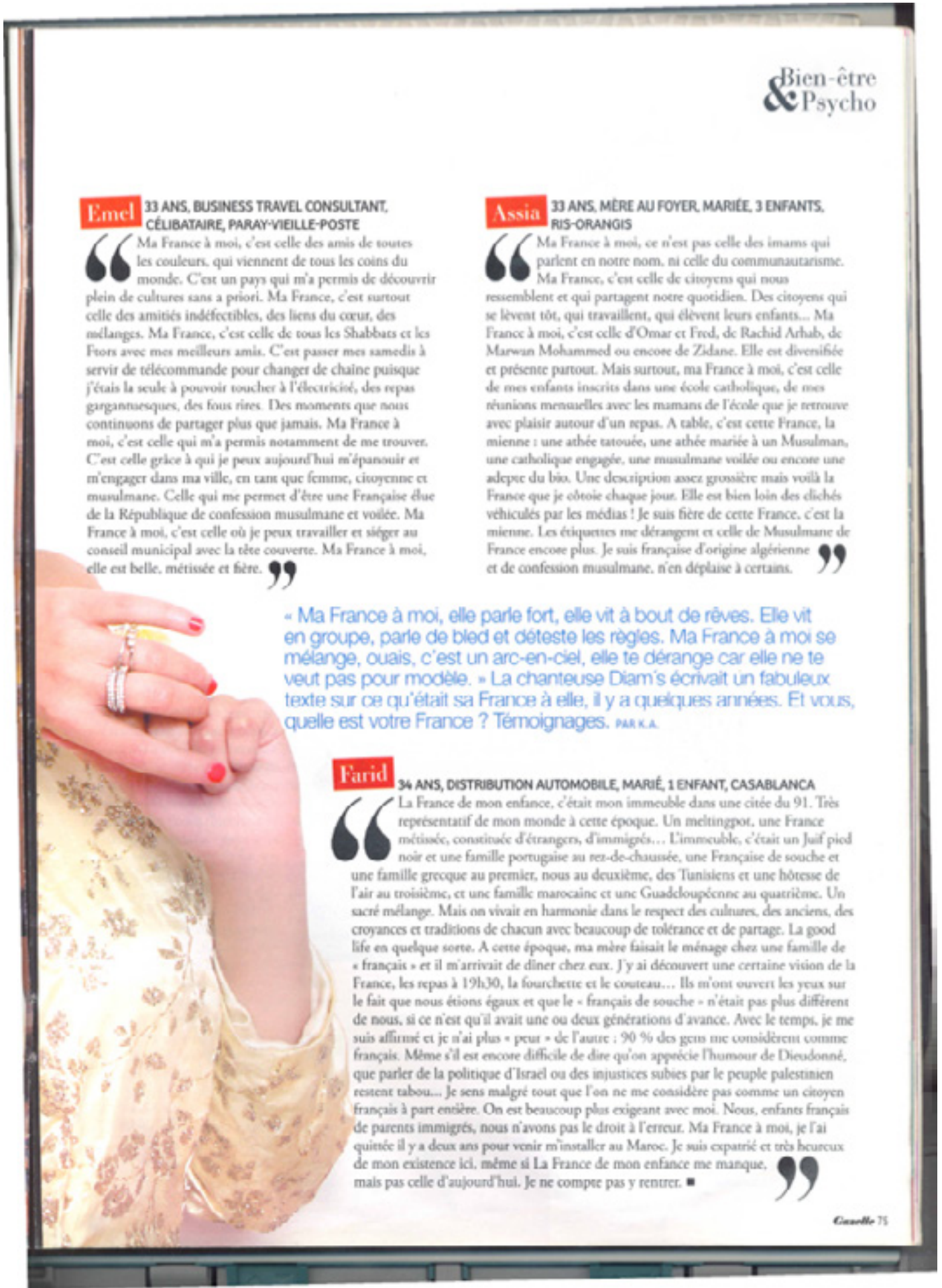

